\title{
Properties of low-formaldehyde-emission particleboard made from recycled wood-waste chips sprayed with $\mathrm{PMDI} / \mathrm{PF}$ resin
}

\author{
Song-Yung Wang ${ }^{\mathrm{a}}$, Te-Hsin Yang ${ }^{\mathrm{a}}$, Li-Ting Lin ${ }^{\mathrm{a}}$, Cheng-Jung Lin ${ }^{\mathrm{b}}$, Ming-Jer Tsai ${ }^{\mathrm{a}, *}$ \\ ${ }^{a}$ School of Forestry and Resource Conservation, National Taiwan University, Taipei, Taiwan, ROC \\ ${ }^{\mathrm{b}}$ Division of Forest Utilization, Taiwan Forestry Research Institute, 53 Nan-Hai Rd., Taipei 100, Taiwan, ROC
}

Received 8 October 2005; received in revised form 2 May 2006; accepted 13 June 2006

\begin{abstract}
The objective of this study was to manufacture low-formaldehyde-emission particleboard from recycled wood-waste chips using polymeric 4,4'-methylenediphenyl isocyanate (PMDI) and phenol-formaldehyde (PF) resins for use in indoor environments. The influence of PMDI/PF ratios in particles on the formaldehyde emission and its mechanical properties were investigated. The experimental results showed that the formaldehyde emission released decreased linearly with increasing PMDI/PF particle ratio. The relationship could be represented by a linear regression formula. Formaldehyde emission was below $0.3 \mathrm{mg} / \mathrm{L}$ when the weight percentage of PMDI/particles was up to $70 \%$. The formaldehyde emission from melamine-formaldehyde (MF) resin-impregnated paperoverlaid particleboard was $17 \%$ lower than that for particleboard. Moreover, the bending strength, internal bonding strength and screw holding strength increased with increasing PMDI/PF particle ratio. However, the percentage thickness swelling of the particleboard decreased with increasing PMDI/PF particle ratio. In addition, there were significant positive relationships between the ultrasonic velocity and the bending strength, internal bonding strength and screw holding strength of the particleboard, which allowed evaluation of the properties of the particleboard using ultrasonic velocity.
\end{abstract}

(C) 2006 Elsevier Ltd. All rights reserved.

Keywords: Quantity of formaldehyde released; Polymeric 4, 4'-methylenediphenyl isocyanate (PMDI); Phenol-formaldehyde resin; Particleboard; Internal bonding strength; Thickness swelling

\section{Introduction}

In recent years, the recycling systems and reuse techniques of wood wastes in Taiwan have become an important part of sustainable utilization of resources. The Taiwanese government has already issued regulations regarding to recycling and reusing wood-based wastes such as flooring, ceiling, and decorations from construction and demolition sites [1]. According to the end uses, wood wastes could be sorted, processed and provided as raw materials for manufacture of pulp, fiberboard and particleboard. In these reuse products, particleboard has found

\footnotetext{
${ }^{*}$ Corresponding author. Tel.: + 886233664641 ; fax: +886223686335 .

E-mail addresses: sywang@ntu.edu.tw (S.-Y. Wang), d90625006@ntu.edu.tw (T.-H. Yang), inmoomni@yahoo.com.tw (L.-T. Lin), d88625002@yahoo.com.tw (C.-J. Lin),tmj@ntu.edu.tw (M.-J. Tsai).
}

typical applications as flooring, wall and ceiling panels, office dividers, bulletin boards, furniture, cabinets, counter tops, and desk tops [2], and it seems that the manufacture of particleboard from recycled wood-based wastes is the most common way to reuse such waste materials.

During the process of using recycled wood wastes for further reutilization, some problems should be taken into consideration, such as formaldehyde can be released from particleboard used as an interior building product due to incompletely reacted urea-formaldehyde (UF), urea-melamine-formaldehyde (UMF), melamine-formaldehyde (MF) or phenol-formaldehyde (PF) resins used in particleboard. Baumann et al. [3] also indicated that emissions from building and furnishing materials, which are frequently constructed from particleboard and medium density fiberboard, are a potentially important contributor of indoor volatile organic compounds (VOCs). As a result, the indoor air quality can deteriorate and a serious health risk 
may arise, especially in modern homes and offices, which are frequently more airtight than older structures. This increases the significance of the role of formaldehyde in inducing illness via immune mechanisms, infectious processes, and direct toxicity. This phenomenon has become known as sick building syndrome (SBS), whereby the occupants of certain affected buildings repeatedly describe a complex range of vague and often subjective health complaints. To overcome these problems related to air quality and health in the indoor environment, the effects of press conditions (press temperature and time), mat moisture content (MC), lower molecular weight UF resins, and additive of formaldehyde scavenger on formaldehyde emissions or using low-formaldehyde and non-formaldehyde resins for the manufacture of various wood-based panels have been extensively studied in the past [4-11].

Moreover, a series of studies has been conducted to investigate the use of non-destructive evaluation (NDE) technologies to aid in the quality assessment of wood-based products [12-14]. These studies yielded similar results and established relationships between the mechanical strength and dynamic properties.

The purpose of this study was to investigate the quantity of formaldehyde released, density, bending properties, internal bonding strength, and thickness swelling of particleboard made from recycled wood chips of different species, which were sprayed with polymeric $4,4^{\prime}$-methylenediphenyl isocyanate (PMDI) for the core layer and with $\mathrm{PF}$ resin for the face and back layers. Furthermore, the ultrasonic properties of the manufactured particleboard were also evaluated.

\section{Materials and methods}

\subsection{Materials}

Chips from mixed hardwood species including oak (Quercus spp.) and lauan (Shorea spp.) were prepared from recycled construction and demolition wastes, which were collected and then classified by Jen-Chun Enterprises in Feng-Yuan, Taiwan.

The adhesives used were a water-soluble PF resin (76-78\% solid content and $\mathrm{pH}$ 8-9; Tai-Lin Resin, Taipei, Taiwan) and a water-soluble PMDI resin $(100 \%$ solid content; Mu-Chau Resin, Tainan, Taiwan). MF resinimpregnated paper was overlaid on the face and back layers of the particleboard.

\subsection{Chip production process}

Chips were divided into coarse chips, which passed through a four-mesh and were retained by an eight-mesh screen, and fine chips, which passed through an eight-mesh and were retained by a 20 -mesh screen. The ratio of coarse/ fine chips used for particleboard was 2:1. The chips were oven-dried to $2-4 \% \mathrm{MC}$ at a temperature of $338 \pm 2 \mathrm{~K}$. They were then sprayed with a water-soluble PMDI or PF
Table 1

Particleboards fabricated for this study

\begin{tabular}{lcr}
\hline Sample group & \multicolumn{2}{c}{ Chip content $(\%)$} \\
\cline { 2 - 3 } & PMDI & PF \\
\hline A & 100 & 0 \\
B & 80 & 20 \\
C & 70 & 30 \\
D & 50 & 50 \\
E & 30 & 70 \\
F & 20 & 80 \\
G & 0 & 100 \\
MD & 50 & 50 \\
MC & 70 & 30 \\
MA & 100 & 0 \\
\hline
\end{tabular}

Sample groups A-G: particleboards. Sample groups MD, MC and MA: MF resin-impregnated paper-overlaid particleboards. PMDI was used for the core layer of the particleboard. PMDI resin absorption was $4 \%$ of the oven-dried weight of the chips. PF was used for the face and back layers of the particleboard. PF resin absorption was $6 \%$ of the oven-dried weight of the chips.

resin according to the experimental program shown in Table 1.

Chips were then placed into a frame of $500 \mathrm{~mm} \times 500 \mathrm{~mm}$. Three-layer particleboard was formed using coarse and fine chips at a ratio of 2:1. A conventional hot press was used for fabrication of the particleboard and the temperature, pressure and pressing time were $453 \mathrm{~K}$, 2.9 $\mathrm{MPa}$ and $5 \mathrm{~min}$, respectively. The nominal dimensions of particleboard were $500 \mathrm{~mm} \times 500 \mathrm{~mm} \times 12 \mathrm{~mm}$ (thick), with three layers. The thickness of the particleboard was controlled by stop bars and the target density was $0.8 \mathrm{~g} /$ $\mathrm{cm}^{3}$. Five samples of each PMDI/PF ratio (weight of chips sprayed with $\mathrm{PMDI} /$ weight of chips sprayed with $\mathrm{PF}$ ) (Table 1) were fabricated in this study. Furthermore, MF resin-impregnated paper-overlaid particleboards with three different PMDI/PF ratios (Table 1) were also manufactured for our experiments.

\subsection{Testing methods}

The particleboards produced for this study were tested in accordance with the Chinese National Standard (CNS 2215), which involves various tests [15].

\subsubsection{Test for the quantity of formaldehyde released}

(1) Acquisition of formaldehyde: A 120-mm-diameter, 60$\mathrm{mm}$-high crystallizing dish containing $300 \mathrm{~mL}$ of distilled water was placed in the bottom of a $240-\mathrm{mm}$ diameter desiccator with a capacity of $10 \pm 1 \mathrm{~L}$. Nine sheets of test pieces (with dimensions of $12 \mathrm{~mm}$ thick $\times 50 \mathrm{~mm}$ wide $\times 150 \mathrm{~mm}$ long) were clamped in a metal support, with no contact between specimens and allowed to stand in the crystallizing dish at $293 \mathrm{~K}$ for $24 \mathrm{~h}$. Formaldehyde released from the specimens was 
absorbed by the distilled water, which was subsequently used as the sample solution.

(2) Quantification of formaldehyde concentration: The formaldehyde concentration in the sample solution was determined using acetylacetone-ammonium acetate solution and the acetylacetone method, with colorimetric detection at $415 \mathrm{~nm}$.

Prior to testing, the particleboards were conditioned at $293 \mathrm{~K}$ and $65 \%$ relative humidity, and full panels of each particleboard were prepared for ultrasonic wave tests. Test points on opposite sides of the particleboard were investigated at intervals of $50 \mathrm{~mm}$. An ultrasonic wave instrument (Pundit, $54 \mathrm{kHz}$; CNS Electronics) was used to measure the time required for the transmission of an ultrasonic pulse through the specimen. The ultrasonic velocity was then calculated from the length of the specimen divided by the propagation time.

After the ultrasonic investigation, the particleboards tested were cut into specimens for static bending and internal bond strength (IB) tests according to CNS 2215 [15], and their positions relative to the full particleboard were recorded. These static bending specimens were first used to measure the ultrasonic velocity (Vl) through the face direction using a Pundit ultrasonic apparatus at a frequency of $54 \mathrm{kHz}$. Then transit times for the ultrasonic pulse were measured at a frequency of $500 \mathrm{kHz}$ through the thickness of each specimen. The velocity was then calculated using the following formula:

$\operatorname{Vl}\left(V_{\mathrm{t}}\right)(\mathrm{m} / \mathrm{s})=\frac{L}{t}$,

where $\mathrm{Vl}$ is the ultrasonic velocity in the face direction of the particleboard, $V_{\mathrm{t}}$ is the ultrasonic velocity through the thickness of the particleboard, $L$ is the length, and $t$ is the transit time.

\subsubsection{Density and moisture content}

Fabricated particleboards were conditioned at ambient humidity for 1 week and then tested for density and MC according to the following formulae:

Air-dried density $\left(\mathrm{g} / \mathrm{cm}^{3}\right)=\frac{W_{\mathrm{a}}}{V_{\mathrm{a}}}$,

Moisture content $(\%)=\frac{W_{\mathrm{a}}-W_{0}}{W_{0}} \times 100$,

where $W_{\mathrm{a}}$ is the air-dried weight, $V_{\mathrm{a}}$ is the air-dried volume, and $W_{0}$ is the oven-dried weight of the particleboard.

\subsubsection{Static bending test}

After the ultrasonic wave tests, bending specimens of $50 \mathrm{~mm}$ wide $\times 230 \mathrm{~mm}$ long were cut from each full particleboard. A concentrated bending load was applied at the center with a span of 15 times the thickness of the specimen. The bending modulus of elasticity (MOE) and modulus of rupture (MOR) were calculated from load- deflection curves according to the following formulae:

$\mathrm{MOR}=\frac{3 P_{\mathrm{b}} L}{2 b h^{2}}$,

$\mathrm{MOE}=\frac{P_{\mathrm{bp}} L^{3}}{4 b h^{3} Y_{\mathrm{p}}}$,

where MOR is the static bending strength (modulus of rupture) (MPa), MOE is the static bending modulus of elasticity $(\mathrm{MPa}), P_{\mathrm{b}}$ is the maximum load $(\mathrm{N}), P_{\mathrm{bp}}$ is the load at the proportional limit $(\mathrm{N}), Y_{\mathrm{p}}$ is the deflection corresponding to $P_{\mathrm{bp}}(\mathrm{mm}), b$ is the width of the specimen $(\mathrm{mm}), h$ is the thickness of the specimen $(\mathrm{mm})$, and $L$ is the span $(\mathrm{mm})$.

\subsubsection{Internal bond strength}

The tensile strength perpendicular to the surface was determined using three conditioned specimens of $50 \mathrm{~mm} \times 50 \mathrm{~mm}$ from each particleboard according to CNS 2215 [15]. The rupture load $\left(P_{\mathrm{s}}\right)$ was determined and internal bond strength was calculated using the following formula:

$\mathrm{IB}=\frac{P_{\mathrm{s}}}{b l}$,

where IB is the internal bond strength (MPa), $P_{\mathrm{s}}$ is the rupture load, and $l$ is the length of the specimen. It should be noted that the ultrasonic velocity of IB specimens was measured as described above before the IB tests.

\subsubsection{Thickness swelling}

Specimens with dimensions of $50 \mathrm{~mm} \times 50 \mathrm{~mm}$ were prepared for evaluation of the thickness swelling according to CNS 2215 [15]. The thickness at the middle of the test specimen was measured with a micrometer. Then the test specimens were placed into water in parallel for $30 \mathrm{~mm}$ and soaked for 2 and $24 \mathrm{~h}$ before further measurement of the thickness. The thickness-swelling rate (TS) was determined from the following formula:

$\mathrm{TS}_{2}=\frac{\left(t_{2}-t_{0}\right)}{t_{0}} \times 100$,

$\mathrm{TS}_{24}=\frac{\left(t_{24}-t_{0}\right)}{t_{0}} \times 100$,

where TS is the thickness swelling rate $(\%), t_{0}, t_{2}$ and $t_{24}$ are the thickness at the middle of the test specimen before soaking, and soaking in water for 2 and $24 \mathrm{~h}$, respectively.

\section{Results and discussion}

\subsection{Quantity of formaldehyde released}

In this study, chips of mixed wood species were sprayed with a water-soluble PMDI or PF resin according to the experimental program shown in Table 1. It was found that the quantity of formaldehyde released decreased linearly 
Table 2

Quantity of formaldehyde released from the particleboards tested and reduction for MF resin-impregnated paper-overlaid particleboard

\begin{tabular}{llllllll}
\hline Sample & \multicolumn{2}{l}{ Formaldehyde released (mg/L) } & & & \\
\cline { 2 - 8 } & A & B & C & D & E & F & G \\
\hline Particleboard & $0.08 \pm 0.02$ & $0.21 \pm 0.03$ & $0.29 \pm 0.02$ & $0.49 \pm 0.06$ & $0.62 \pm 0.04$ & $0.73 \pm 0.06$ & $0.86 \pm 0.03$ \\
MF resin-impregnated paper overlaid particleboard & $0.06 \pm 0.03$ & $0.17 \pm 0.05$ & $0.24 \pm 0.03$ & $0.41 \pm 0.04$ & $0.53 \pm 0.06$ & $0.61 \pm 0.03$ & $0.71 \pm 0.05$ \\
Reduction rate (\%) & 16.81 & 17.10 & 16.38 & 17.78 & 14.52 & 16.60 & 17.44 \\
\hline
\end{tabular}

Table 3

Correlation among the quantity of released formaldehyde (FR), ultrasonic wave velocity (V), modulus of rupture (MOR), modulus of elasticity (MOE), internal bonding strength (IB) and screw holding strength (SH) analyzed by linear regression $(Y=A X+B)$ formulae for tested particleboard

\begin{tabular}{|c|c|c|c|c|c|c|}
\hline \multirow[t]{2}{*}{ Sample } & \multicolumn{6}{|c|}{$Y=A X+B$} \\
\hline & $Y$ & $X$ & $A$ & $B$ & $r^{2}$ & $F$ \\
\hline \multirow[t]{5}{*}{ Particleboard } & FR & $\mathrm{PMDI} / \mathrm{PF}$ & 0.0081 & 0.06 & 0.99 & $142^{* *}$ \\
\hline & MOR & $\mathrm{Vl}$ & 0.02 & -31.88 & 0.73 & $132^{* *}$ \\
\hline & MOE & $\mathrm{Vl}$ & 1.87 & -1751.40 & 0.78 & $172^{* *}$ \\
\hline & IB & $V_{\mathrm{t}}$ & 0.001 & -0.20 & 0.71 & $116^{* *}$ \\
\hline & $\mathrm{SH}$ & $V_{\mathrm{t}}$ & 0.274 & -170.52 & 0.95 & $37^{* *}$ \\
\hline \multirow[t]{4}{*}{ MF resin-impregnated paper-overlaid particleboard } & FR & $\mathrm{PMDI} / \mathrm{PF}$ & 0.0066 & 0.06 & 0.99 & $102^{* *}$ \\
\hline & MOR & $\mathrm{Vl}$ & 0.04 & -77.3 & 0.71 & $79^{* *}$ \\
\hline & MOE & $\mathrm{Vl}$ & 0.03 & -52.45 & 0.87 & $206^{* *}$ \\
\hline & IB & $V_{\mathrm{t}}$ & 0.007 & 0.033 & 0.87 & $194^{* *}$ \\
\hline
\end{tabular}

FR, quantity of formaldehyde released $(\mathrm{mg} / \mathrm{L})$; PMDI/PF ratio (\%), ratio (\%) of chip weight sprayed with PMDI to chip weight sprayed with PF in the particleboard; MOR, modulus of rupture; MOE, modulus of elasticity; IB, internal bonding strength; SH, screw holding strength; Vl, ultrasonic velocity propagated through the face direction of the particleboard; $V_{\mathrm{t}}$, ultrasonic velocity propagated through the thickness of the particleboard.

** Significant difference at the $1 \%$ level $(P<0.01)$.

with increasing PMDI/PF ratio (weight of chips sprayed with PMDI/weight of chips sprayed with PF) (Table 2).

Linear regression analysis showed a high degree of correlation $\left(r^{2}=0.99\right)$ between the quantity of formaldehyde released and the PMDI ratio for the particleboards tested.

The quantity of formaldehyde released from various PMDI/PF particleboards is shown in Table 2. For samples in group $\mathrm{D}$, with a PMDI/PF ratio of 50:50, the quantity of formaldehyde released was $0.49 \mathrm{mg} / \mathrm{L}$, which meets the $E_{0}$ standard $(<0.50 \mathrm{mg} / \mathrm{L})$ of CNS 2215 [15]. Moreover, the quantity of formaldehyde released was $0.29 \mathrm{mg} / \mathrm{L}$ $(<0.30 \mathrm{mg} / \mathrm{L})$ from group $\mathrm{C}$ samples with a PMDI/PF ratio of $70: 30$.

One of the advantages of using PMDI was no formaldehyde emission, hence, the more PMDI/PF ratio sprayed on particle, the less formaldehyde released from particleboard, and one possible explanation for the reduction in formaldehyde from particleboard bonded with PMDI adhesive is that the PMDI molecules can react with water rapidly during hot-pressing to form amines, which can further react with other PMDI molecules to produce PMDI polymers [16].

The similar report also illustrated that the PMDI may have cured faster, and the PMDI adhesive film on the particle surfaces may have prevented VOCs volatilizing from the particle surfaces [11].

The quantity of formaldehyde released from MF resinimpregnated paper-overlaid particleboard decreased with increasing PMDI/PF ratio, as shown in Table 2. This relationship could be represented by a linear regression formula (Table 3). The relationship between the quantity of formaldehyde released and the PMDI/PF ratio for the particleboards and MF resin-impregnated paper-overlaid particleboard samples is demonstrated in Fig. 1.

In comparison to the quantity of formaldehyde released from the particleboards tested and that released from MF resin-impregnated paper-overlaid particleboards was $10-21 \%$ lower, as shown in Table 2 . In a study by Wiglusz et al. [10], the quantity of formaldehyde released from UF resin particleboard overlaid with a decorative paper foil in the early period after manufacture was $30 \%$ lower than that of UF resin-impregnated particleboard.

\subsection{Bending properties and ultrasonic velocity}

Results for the bending properties and ultrasonic velocity ( $\mathrm{Vl}$ ) of specimens are listed in Table 4 . It is evident that MOR and MOE values increased with increasing PMDI/PF ratio. In a comparison between PMDI- and 


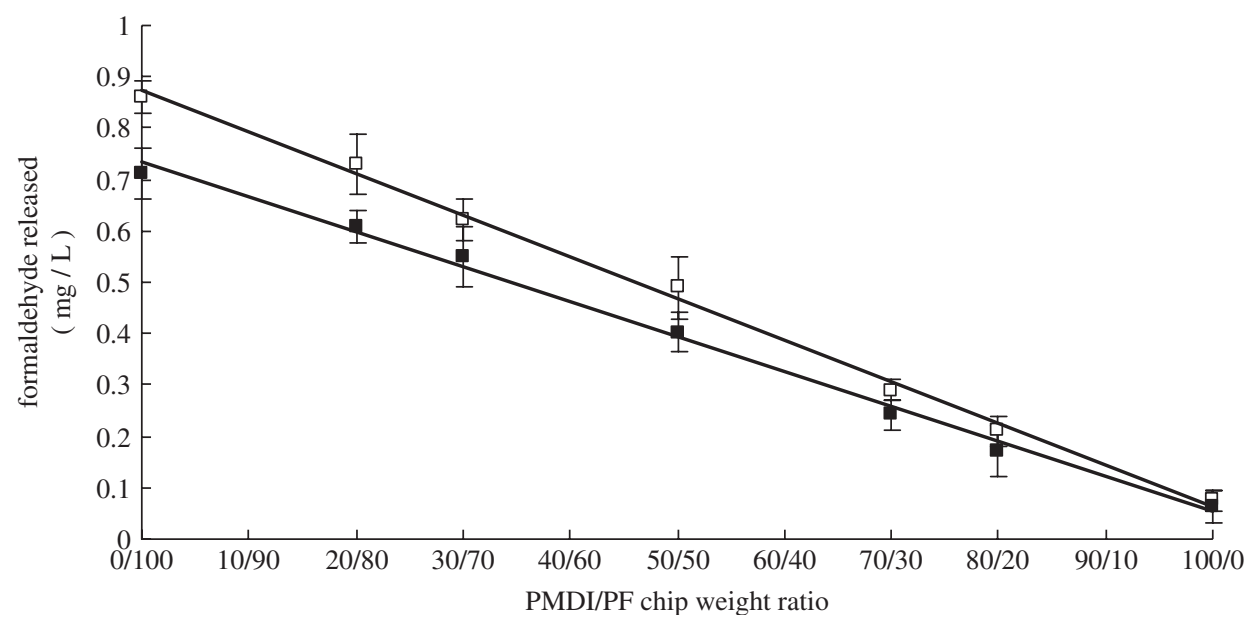

Fig. 1. Relationship between the quantity of formaldehyde released and PMDI/PF ratio. PMDI/PF ratio: weight of chips sprayed with PMDI/weight of chips sprayed with PF $\square$ : particleboard; $\mathbf{\square}$ : MF resin-impregnated paper-overlaid particleboard.

Table 4

Air-dried density, modulus of rupture (MOR), modulus of elasticity (MOE), ultrasonic wave velocity (Vl), internal bonding strength (IB), screw holding strength $(\mathrm{SH})$, thickness swelling (TS) and ultrasonic velocity $\left(V_{\mathrm{t}}\right)$ of tested particleboard sprayed with various PMDI/PF ratios

\begin{tabular}{|c|c|c|c|c|c|c|c|c|}
\hline Sample group & Air-dried density $\left(\mathrm{g} / \mathrm{cm}^{3}\right)$ & MOR (MPa) & $\operatorname{MOE}\left(\times 10^{2} \mathrm{MPa}\right)$ & $\mathrm{Vl}(\mathrm{m} / \mathrm{s})$ & IB (MPa) & $\mathrm{SH}(\mathrm{N})$ & TS $(\%)$ & $V_{\mathrm{t}}(\mathrm{m} / \mathrm{s})$ \\
\hline G & $0.81 \pm 0.03$ & $11.4 \pm 0.8$ & $20.8 \pm 1.0$ & $2112 \pm 52.6$ & $0.56 \pm 0.02$ & $507.6 \pm 64.0$ & $18.1 \pm 2.3$ & $823 \pm 37.6$ \\
\hline $\mathrm{D}$ & $0.82 \pm 0.02$ & $16.1 \pm 1.2$ & $25.1 \pm 1.8$ & $2271 \pm 177.4$ & $0.62 \pm 0.02$ & $638.0 \pm 45.7$ & $14.2 \pm 2.5$ & $865 \pm 50.1$ \\
\hline $\mathrm{C}$ & $0.82 \pm 0.02$ & $17.0 \pm 0.9$ & $26.5 \pm 1.2$ & $2302 \pm 30.6$ & $0.65 \pm 0.01$ & $740.9 \pm 46.8$ & $11.8 \pm 1.9$ & $873 \pm 51.1$ \\
\hline B & $0.79 \pm 0.03$ & $21.2 \pm 1.1$ & $27.9 \pm 1.1$ & $2446 \pm 26.3$ & $0.68 \pm 0.03$ & $799.7 \pm 37.5$ & $10.6 \pm 1.4$ & $891 \pm 52.2$ \\
\hline A & $0.81 \pm 0.04$ & $23.2 \pm 1.8$ & $30.9 \pm 0.7$ & $2520 \pm 122.8$ & $0.73 \pm 0.02$ & $848.7 \pm 55.1$ & $7.1 \pm 1.1$ & $938 \pm 67.1$ \\
\hline MD & $0.83 \pm 0.02$ & $18.9 \pm 1.6$ & $28.9 \pm 1.8$ & $2367 \pm 36.0$ & $0.62 \pm 0.03$ & $752.6 \pm 42.1$ & $13.8 \pm 2.3$ & $836 \pm 47.6$ \\
\hline $\mathrm{MC}$ & $0.83 \pm 0.02$ & $19.6 \pm 1.9$ & $31.1 \pm 2.9$ & $2451 \pm 83.2$ & $0.65 \pm 0.03$ & $847.7 \pm 46.3$ & $10.1 \pm 1.5$ & $851 \pm 53.0$ \\
\hline MA & $0.82 \pm 0.04$ & $27.9 \pm 1.2$ & $34.5 \pm 1.6$ & $2533 \pm 77.9$ & $0.73 \pm 0.03$ & $936.9 \pm 50.4$ & $7.0 \pm 1.6$ & $939 \pm 63.3$ \\
\hline
\end{tabular}

Sample groups A, B, C, D and G: particleboards. Sample groups MD, MC and MA: MF resin-impregnated paper-overlaid particleboards.

PF-impregnated particleboards of the same density [17], higher MOE and MOR values were found for the PMDIsprayed particleboards, similar to the results of our study. Except for group G, the MOR values for samples in groups A-F meet standard 13 (MOR > 13 MPa) of CNS 2215. Furthermore, the MOR values for groups $\mathrm{A}$ and $\mathrm{B}$ meet standard 18 (MOR $>18 \mathrm{MPa}$ ) of CNS 2215. With regard to MOE values, group A samples meet standard 18 $(2998.8 \mathrm{MPa})$ and groups B, C, and D meet standard 13 (2499 MPa), whereas group $\mathrm{G}$ could only meet standard 8 (1999.2 MPa) of CNS 2215 [15].

The bending properties and ultrasonic velocity of MF resin-impregnated paper-overlaid particleboards with a PMDI/PF ratio of 50:50 (group MD), 70:30 (group MC) and 100:0 (group MA) are also shown in Table 4. In comparison to the bending properties of sample groups D, $\mathrm{C}$ and $\mathrm{A}$, the MOR values for groups $\mathrm{MD}, \mathrm{MC}$ and $\mathrm{MA}$ were $17.69 \%, 15.81 \%$ and $20.11 \%$, whereas the MOE values were $14.86 \%, 17.64 \%$ and $11.92 \%$ higher, respectively. After retrofitting particleboard with MF resinimpregnated paper overlaid on the face and back layers, the bending strength of the MC group met standard 18 of CNS 2215 [15].
Values for the ultrasonic velocity (Vl) are shown in Table 4. It is evident that the ultrasonic velocity propagated in the mechanical direction (Vl) increased with increasing $\mathrm{PMDI} / \mathrm{PF}$ ratio. In addition, there were significant positive relationships between the ultrasonic velocity and the bending strength, as shown in Table 3.

\subsection{Internal bond strength}

High internal bond strength was observed for the particleboards with different PDMI/PF ratios in our study because of the even distribution of the PDMI/PF resin on the chips. The IB values of the PMDI/PF-resin particleboards in our study meet standard 18 of CNS 2215 and are superior to those for PF resin-sprayed particleboards (0.12-0.42 MPa) [18]. Compared to particleboard manufactured from mixed species [19], including pine, aspen, oak and other hardwoods $(\mathrm{IB}=0.56 \mathrm{MPa})$, the $\mathrm{IB}$ values in our study are also higher.

Bao et al. [20] established a PMDI bonding model by 2D NMR and illustrated the relationship between wood and PMDI. The major components formed from the curing of PMDI in wood are urea structures arising from the 
reaction with water. PMDI can penetrate into the wood cells and into the middle lamellae between the wood cells, where it reacts with the available moisture stored in the wood to form either linear urea structures and/or crosslinking biuret/dimmer/trimer structures. In addition, the PMDI may react with the chemical components (the hydroxyl groups in polysaccharide or the lignin phenolic groups) of the wood to form urethane structures, and can further contribute to adhesion. The crosslinking can also serve to increase the rigidity of the plywood, especially at high levels of crosslinking.

Johns et al. [17] compared the same densities of particleboards, which were manufactured by PMDI, EMDI, UF and PF resin. The results indicated that the IB values of particleboard manufactured by PMDI and EMDI resin were higher than those of particleboard manufactured by UF and PF resin.

However, IB values for experimental particleboard and MF resin-impregnated paper-overlaid particleboard were not significantly different from each other (Fig. 2). This is because the IB depends on the bonding effect of chips in the core layer of particleboard, rather than on any retrofitting on the face and back layers.

Moreover, IB values increased linearly with increasing ultrasonic wave velocity through the thickness of the particleboard (Table 3). This result is in agreement with a previous study of particleboard in which a high correlation was reported between ultrasonic velocity measured along the length or thickness and the IB, with $r^{2}$ values of 0.66 and 0.92 , respectively [13]. Previous studies also indicated a high degree of correlation between ultrasonic wave velocity propagated through the thickness and the IB of PF resinimpregnated OSB [21-23]. This suggests that the ultrasonic velocity could be satisfactorily used to assess the IB of boards.

\subsection{Thickness swelling}

Results for the thickness swelling of particleboards manufactured in our study for groups A, B, C, MA and MC were lower than $12 \%$ (Fig. 3 and Table 4) and meet standard 8 of CNS 2215 [15]. Table 4 also shows that the thickness swelling decreased with increasing PMDI/PF ratio. The reason for this relationship is possibly a swelling effect induced by PMDI. In comparison to the thickness swelling of the particleboards tested, no significant effect was observed for retrofitting with MF resin-impregnated paper overlaid on the particleboard, as shown in Table 4.

\subsection{Screw holding strength}

Table 4 shows that the screw holding strength ( $\mathrm{SH})$ of particleboards manufactured in our study was $508.0-849.3 \mathrm{~N}$, which is higher than the values measured for urea adhesive particleboards $(413.8-668.9 \mathrm{~N})$ fabricated by Wang and Chen [18]. Moreover, compared to the quality of particleboard type 18 according to the CNS 2215
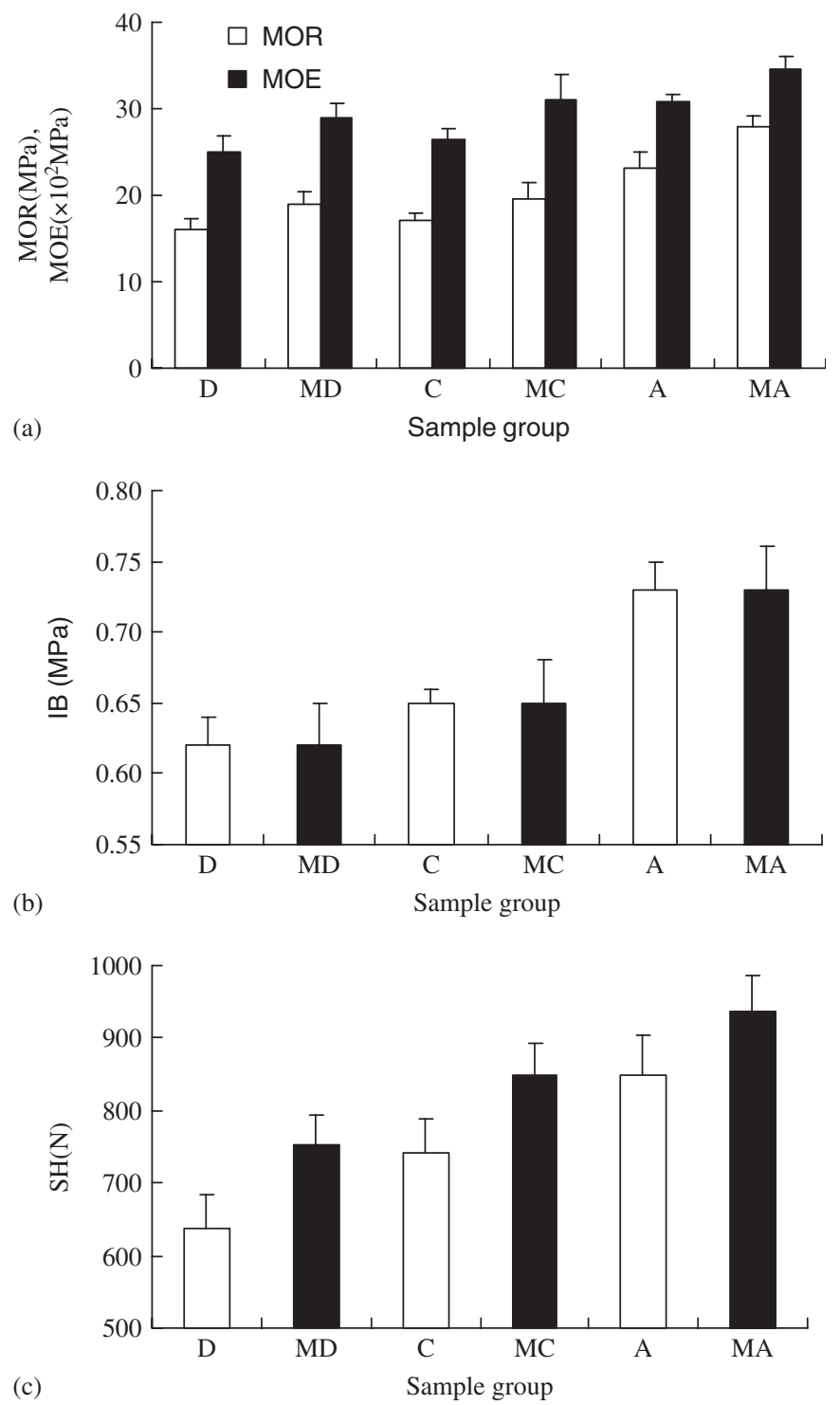

Fig. 2. (a) Modulus of rupture (MOR), modulus of elasticity (MOE), (b) internal bonding strength (IB) and (c) screw holding strength (SH) for various particleboards. Sample groups A, C and D: particleboards. Sample groups MD, MC and MA: MF resin-impregnated paper-overlaid particleboards.

standard $(500.1 \mathrm{~N})$, higher SH values were observed for the different particleboard groups in our study. Moreover, the $\mathrm{SH}$ values increased with increasing PMDI/PF ratio. The results could be represented by linear formulae, as shown in Table 3. Table 3 also shows that there was a high degree of correlation between $\mathrm{SH}$ and the ultrasonic velocity.

\section{Conclusions}

This study investigated the quantity of formaldehyde released and the properties of particleboard produced using recycled wood-waste particles with different PMDI/PF ratios. Results showed that $0.49 \mathrm{mg} / \mathrm{L}$ of formaldehyde was released for group D samples (with a PMDI/PF ratio of 50:50), which meets the $E_{0}$ standard of CNS 2215, whereas 


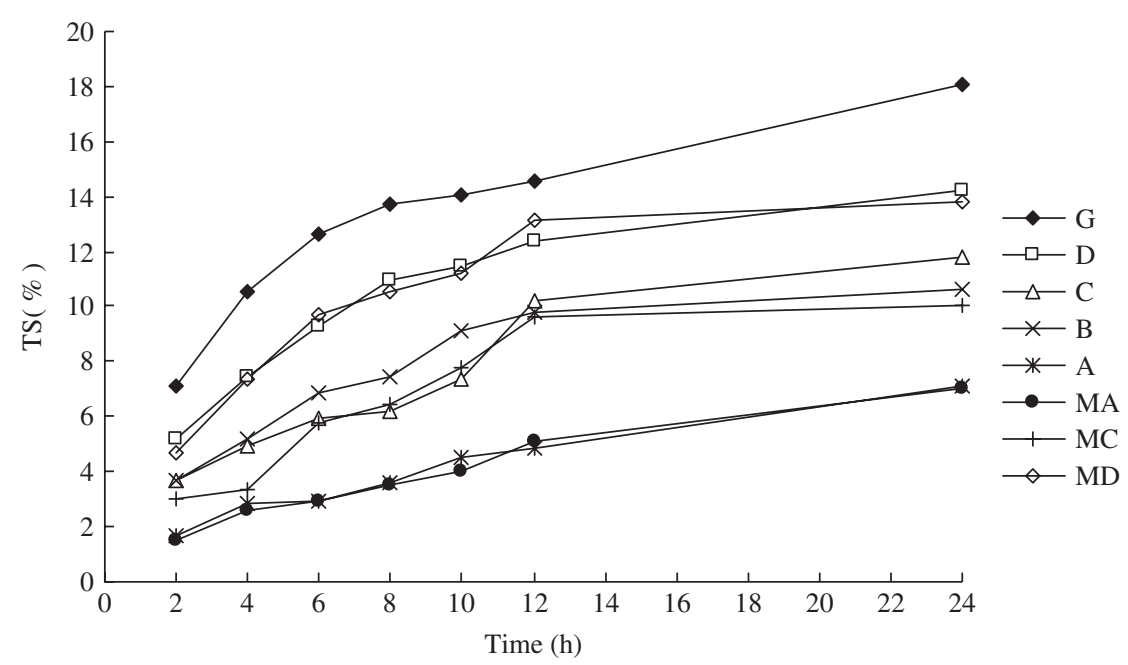

Fig. 3. Thickness swelling (\%) for various PMDI/PF ratios in the particleboards tested in $24 \mathrm{~h}$. Sample groups A, B, C, D and G: particleboards. Sample groups MD, MC and MA: MF resin-impregnated paper-overlaid particleboards.

for samples with a PMDI/PF ratio up to $70: 30,<0.3 \mathrm{mg} / \mathrm{L}$ formaldehyde was released. The quantity of formaldehyde released from MF resin-impregnated paper-overlaid particleboard was $17 \%$ lower than that for particleboard.

The MOR, IB, TS and SH results for PMDI/PF particleboard samples of groups A and MC were superior to those for conventionally manufactured particleboard and could meet standard 18 of CNS 2215. However, the TS for group D was higher than $12 \%$ and could not meet the CNS 2215 standard. In addition, MF resin-impregnated paper overlaid on the face and back layers of particleboard significantly decreased the quantity of formaldehyde released, and increased the MOE and MOR, but showed no significant effect on IB and TS.

The negative relationships between the quantity of formaldehyde released and the PMDI/PF ratio could be represented by linear regression formulae. The ultrasonic wave velocity through the face direction (Vl) increased linearly with increasing MOR and MOE. However, the ultrasonic wave velocity through the thickness of the particleboard $\left(V_{\mathrm{t}}\right)$ increased linearly with increasing internal bond strength and with decreasing thickness swelling. This suggests that ultrasonic velocity can be used to assess the properties of PMDI/PF particleboard.

\section{Acknowledgments}

The authors wish to thank the Council of Agriculture, Forestry Bureau, ROC for the financial support under 93AS-2.3.3-FB-e1.

\section{References}

[1] Ho MC, Wang SY, Tsai MJ, Peng WT, Yang TH, Huang LC, et al. Strategic study on the recovery and utilization of wood wastes. Forest Products Industries 2003;22(3):155-66.
[2] Wang D, Sun XS. Low density particleboard from wheat straw and corn pith. Industrial Crops and Products 2002;15:47-50.

[3] Baumann MGD, Lorenz LF, Batterman SA, Zhang GZ. Aldehyde emission from particleboard and medium density fiberboard products. Forest Products Journal 2000;50(9):75-82.

[4] Minemura N. To lessen formaldehyde liberation from the urea resin glued plywood. Wood Industry 1976;31(12):8-12.

[5] Liu CT. Formaldehyde emission and liberated method of urea resin glued plywood and its processing materials. In: Plywood manufacturing techniques and management. Chinese Forest Products Industry Association; 1985. p. 57-67.

[6] Liu CT. Detected and liberated method of formaldehyde emission from particleboards. In: Proceedings of Processing Techniques and Utilization. Chinese Forest Products Industry Association; 1987. p. $95-103$.

[7] Hao BY, Liu ZhT. The primary study on straw particleboard. Wood Industry 1993;7(3):2-6.

[8] Wang WL, Gardner DJ. Investigation of volatile organic compound press emissions during particleboard production. Part I. UF-bonded southern pine. Forest Products Journal 1999;49(3):65-75.

[9] Grigoriou AH. Straw-wood composites bonded with various adhesive systems. Wood Science and Technology 2000;34:355-65.

[10] Wiglusz R, Nikei G, Igielska G, Sitko E. Volatile organic compounds emissions from particleboard veneered with decorative paper foil. Holzforschung 2002;56(1):108-10.

[11] Wang WL, Gardner DJ, Baummann MGD. Factors affecting volatile organic compound emissions during hot-pressing of southern pine particleboard. Forest Products Journal 2003;53(3):65-72.

[12] Ross RJ, Pellerin RF. NDE of wood based composites with longitudinal stress wave. Forest Products Journal 1988;38(5): 39-45.

[13] Sun YC, Arima T. Structural mechanics of wood composite material: Ultrasonic evaluation of internal bond strength daring an accelerated aging test. Journal of Wood Science 1998;44(3):348-53.

[14] Sun YC, Arima T. Structural mechanics of wood composite material: Ultrasonic propagation mechanism and internal bonding of particleboard. Journal of Wood Science 1999;45(2):221-6.

[15] Chinese National Standard CNS 2515. Particleboards. Bureau of Standards, Metrology and Inspection, 1999.

[16] Wendler SL, Ni J, Frazier CE. Analysis of the isocyanate-wood adhesive bonding using $15 \mathrm{~N} \mathrm{CP} / \mathrm{MAS}$ NMR. In: Wood Adhesives. Madison. WI: Forest Prod. Soc.; 1995. p. 37-42.

[17] Johns WE, Maloney TM, Huffaker EM, Saunders JB, Lentz MT. Isocyanate binders for particle-board manufacture. In: Maloney TM, 
editor. Proceedings of the 15 th Washington State University international symposium on particle board. Pullman, WA: Washington State University; 1981. p. 213-39.

[18] Wang SY, Chen BJ. Studies on the application of Japanese fir particle for the improvement of domestic particleboard processing properties. Forest Products Industries 1986;5(1):2-14.

[19] Xu W, Suchsland O. Variability of particleboard properties from single- and mixed-species processes. Forest Products Journal 1998;48(9):68-74.

[20] Bao S, Daunch WA, Sun Y, Rinaldi PL, Marcinko JJ, Phanopoulos C. Solid state two-dimensional NMR studies of polymeric diphe- nylmethane diisocyanate (PMDI) reaction in wood. Forest Products Journal 2003;53(6):63-71.

[21] Yang TH, Tsai MJ, Wang SY. Characteristics of OSB made from PFresin impregnated flakes. Forest Products Industries 2001;20(3): 227-37.

[22] Yang TH, Chen BJ, Wang SY. Properties of the lightweight OSB made from PF-resin impregnated flakes. Forest Products Industries 2002;21(1):39-50.

[23] Yang TH, Chen HC, Wang SY, Tsai MJ. Characteristics of veneer overlaid OSB by using nondestructive test method. Quarterly Journal of Chinese Forestry 2003;36(2):199-209. 